\title{
The algorithm of steam soot blowers operation based on the monitoring of fouling factors of heating surfaces of a coal-fired boiler under operating conditions
}

\author{
Maciej Bujalski, Maciej Żyrkowski, Daniel Nabagło and Krzysztof Szczepanek \\ PGE Energia Ciepła S.A., Department of Research and Development, \\ Ciepłownicza 1, 31-587 Kraków
}

\begin{abstract}
The article deals with the problem of optimizing the operation of soot blowers in a pulverized coal-fired boiler based on the instantaneous degree of cleanliness of heating surfaces, determined in real time. The elaborated methodology of calculations and the algorithm that determines the optimal configuration of the blowers operation has been implemented and tested on a boiler with a capacity of $380 \mathrm{t} / \mathrm{h}$. The indicator defining the degree of cleanliness of a given heating surface is calculated using available measurements of process parameters based on the epsilon-NTU method. The calculations are carried out in the DCS system for each surface individually (air and water heaters, evaporator, superheaters). During the standard operation of the boiler, the adopted methodology was verified, having analysed the usefulness of the tool to assess the boiler cleanliness under operating condition.
\end{abstract}

\section{Introduction}

Solid fuel power boilers are susceptible to fouling and slagging of heating surfaces. These phenomena are highly undesirable, because they limit the share of heat taken over by the boiler's heating surfaces, which then reduces the efficiency of boiler operation and can lead to expensive failures. For example, the steam superheater can be damaged if the preceding surface is heavily contaminated and does not absorb the appropriate amount of heat from the flue gas. In order to maintain the cleanliness of the boiler, cleaning methods are used such as e.g. soot blowers (including steam, water and air blower), shock wave generators or acoustic blowers. Depending on the type of the object and the fuel burned, the power boilers may differ in the type and number of mounted blowers. The decision on the blowers engaging may be dependent on the operator of the power unit that systematically monitors the boiler's physical parameters, also on the cleaning schedule or on the indications of the dedicated system. This article presents the principle of operation and experience from the functioning of the system for controlling the operation of steam soot blowers. 


\section{Description of the facility}

The system for controlling the operation of soot blowers was implemented on the OP380 pulverized coal fired boiler manufactured by the Polish company RAFAKO. It is a drumtype boiler utilizing hard coal, with a tangential system of burners, characterized by a nominal capacity of $380 \mathrm{t} / \mathrm{h}$ of live steam flow rate. The nominal physical parameters of superheated steam are $\mathrm{T}=540{ }^{\circ} \mathrm{C}$ and $\mathrm{p}=13.5 \mathrm{MPa}$ with boiler efficiency at the level of approx. $91 \%$. The boiler works with a steam condensing-bleeder turbine and is equipped with a steam reheating system. The boiler has four coal mills, each of which works for a separate level of burners. The burners form a low-emission combustion zone with an excess air coefficient of $\lambda<1$. The boiler's cross section is shown in Fig. 1. Above the combustion chamber there are nozzles supplying the post-combustion air stream and the AGAM flue gas temperature measurement system. AGAM system is part of the SNCR type (Selective Non-Catalytic Reduction) installation.

The boiler has three stages of live steam superheater $(\mathrm{SH})$ and three stages of reheater $(\mathrm{RH})$. Water economizer (ECO) located at the flue gas outlet from the second pass. In addition, the facility is equipped with two rotary air pre-heaters (LUVO).

Steam soot blowers are used to clean the boiler under operating condition. A total of 24 blowers plus an additional 4 on rotary air heaters were installed on the boiler (Fig. 1). Within the evaporator and combustion chamber there are 12 pieces of short blowers (numbers 1-12), while in the remaining part of the boiler there are long blowers.
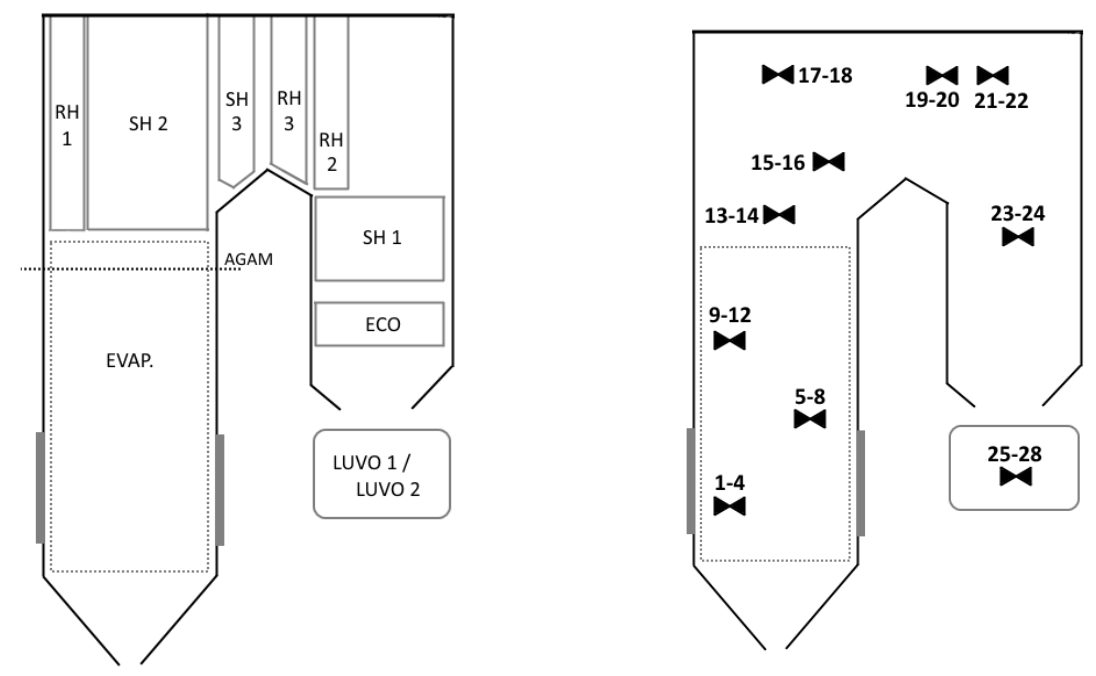

Fig. 1. Diagram of the OP380 boiler with marked heating surfaces (on the left) and arrangement of soot blowers (on the right).

\section{Contamination process of the boiler}

Fig. 2 shows the flue gas temperature distribution at several characteristic points in the boiler. Additionally, the three boiler zones are marked with numbers, which are characteristic due to the type of deposits formed in these areas. Fouling is a phenomenon in which ash particles settle on the heating surfaces of the boiler creating usually easy to remove deposits. This is a process that takes place in the convection zone of the boiler, where the flue gas temperatures 
are below $1000{ }^{\circ} \mathrm{C}$. In zone 2 , there is a high temperature deposit containing mainly calcium (Ca) and sodium $(\mathrm{Na})$ sulphates as well as silicon ( $\mathrm{Si}$ ) compounds. These deposits may be more difficult to remove due to clumping of particles, caused by the occurrence of amorphous deposits in this part of the boiler. In zone 3, low temperature deposits are formed, mainly composed of calcium sulphates $(\mathrm{Ca})$. Another type of contamination will be created as a result of the slagging process. In zone 1, the inorganic matter contained in the burned fuel will occur in the liquid phase or at the interface between the liquid and solid phases. When contacting the surface of the evaporator or any of the superheaters located in the first pass of the boiler, it will be rapidly cooled, and consequently, phase change will occur. As a result, a viscous deposit with a crystalline, amorphous or crystalline-amorphous structure will be created. This process takes place in the radiation zone of the boiler and is particularly dangerous due to deposits that are difficult to remove [1-3].

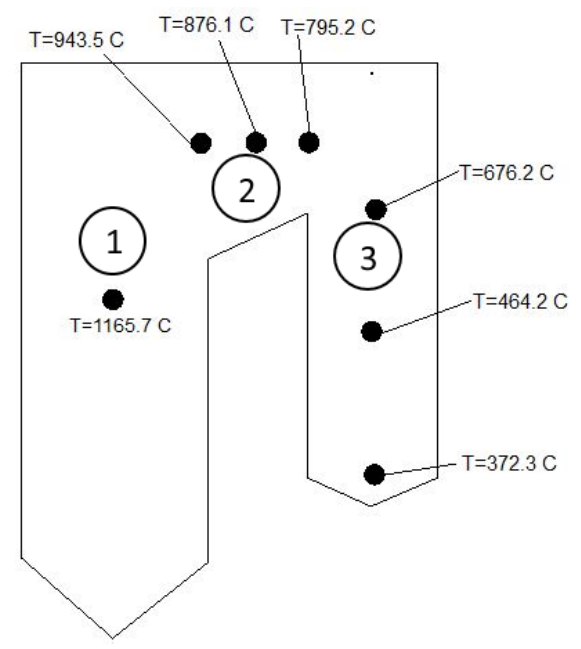

Fig. 2. Diagram of the boiler with marked flue gas temperature at various boiler points and three characteristic zones due to deposit formation.

Lack of regular cleaning of the surfaces can lead to a situation where standard methods of cleaning the boiler (e.g. with the use of soot blowers) will not be able to remove the resulting contamination. Intensity of fouling and slagging phenomena depends, among others, on the composition of the fuel burned and the combustion temperature as well as the boiler load. For operation with a lower load, a reduced volume of exhaust gases will mean a faster decrease in temperature and consequently a shift of characteristic zones due to the formation of deposits. Fuel has a higher potential for contamination if it has a higher content of alkaline elements [4]. Fig. 3 presents a graph illustrating the total operation time of the soot blowers installations in periods (about 6 weeks each), when the coal itself and coal with the addition of biomass were burned (about $20 \%$ by mass). As you can see, co-firing of biomass results in a significant increase in the frequency of cleaning.

Fig. 3 presents the impact of the boiler pollution process on the value of flue gas negative gauge pressure before SH1 superheater. As it can be seen, as a result of the build-up of the deposit layer, the negative pressure in the second boiler pass can increase up to two times. The negative gauge pressure growth process is visible relatively late, because only in about 1250 hours of boiler operation. Fig. 4 shows the influence of the contamination process on the value of flue gas temperature in the second boiler pass (before SH1 superheater). The temperature of the flue gas increases as the layer of deposits builds up on heated surfaces, which consequently reduce heat transfer between flue gases and steam. 

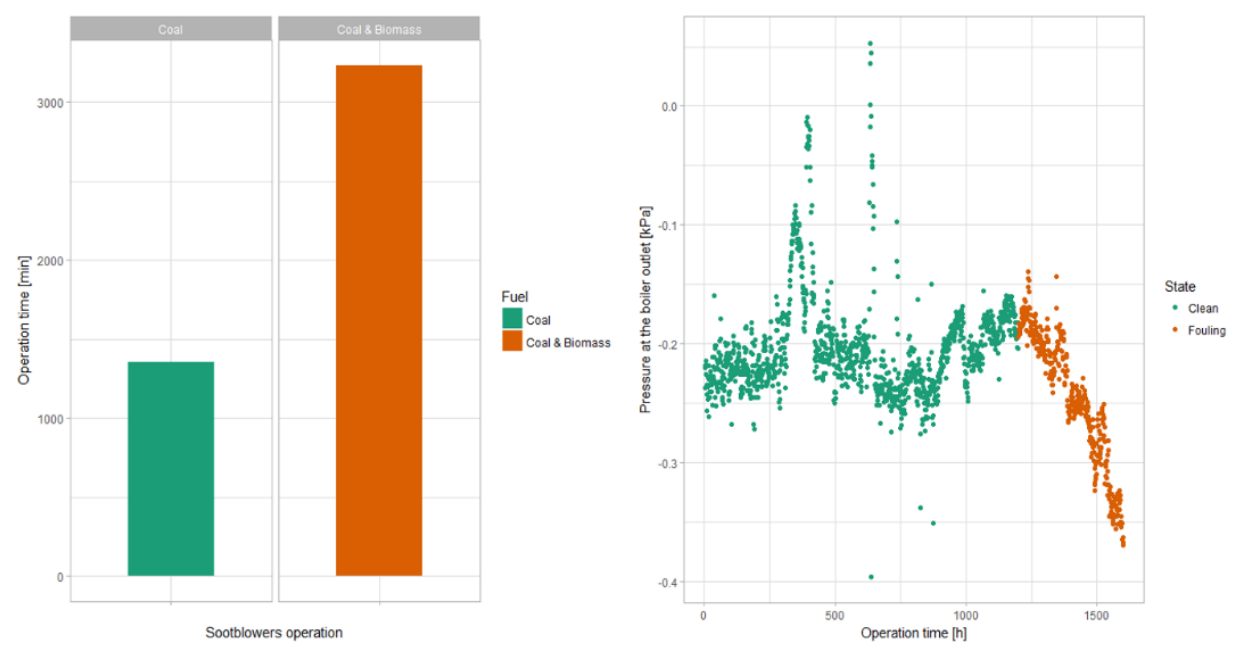

Fig. 3. Total operating time of soot blowers for the period when only coal and coal with the addition of biomass were burned (left) and impact of the fouling process on the value of flue gas negative gauge pressure in the second pass.
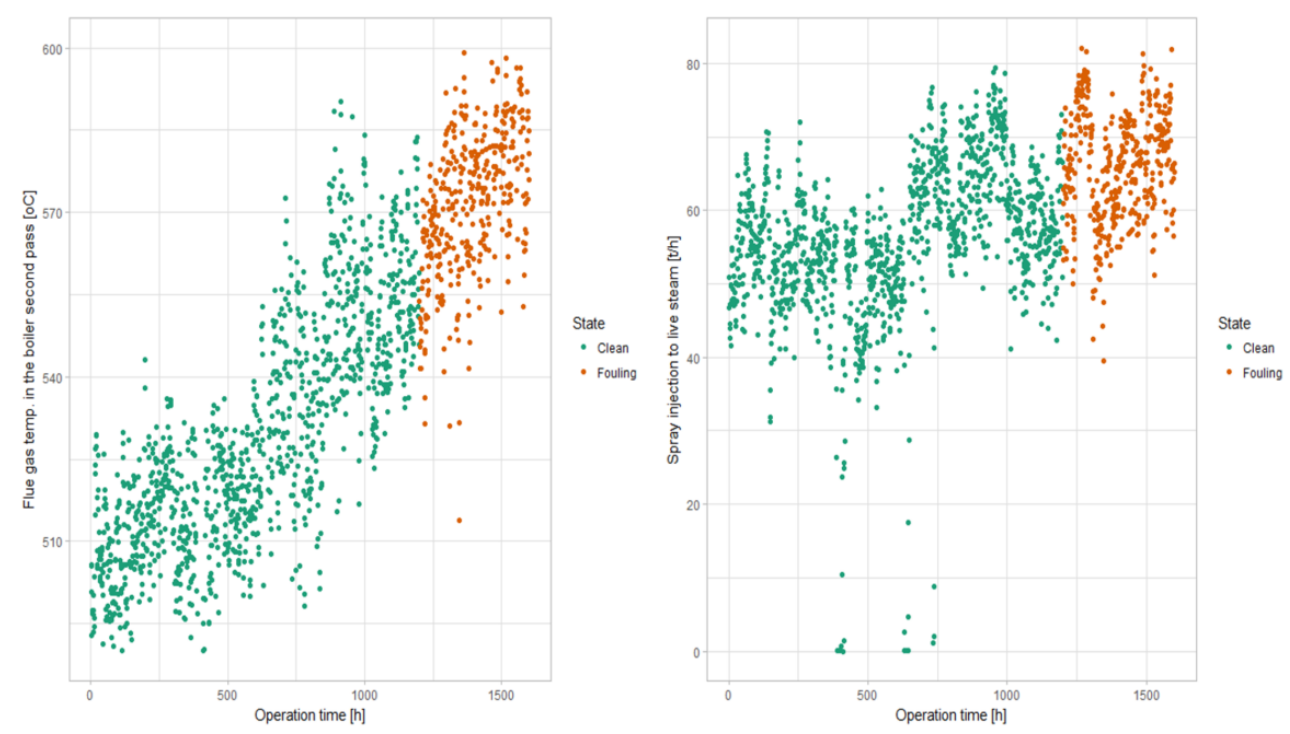

Fig. 4. The flue gas temperature (left) and spray water mass flow rate in the superheated steam circuit (right).

The increase in the contamination of heating surfaces has an impact on the boiler efficiency, both by deteriorating the heat transfer as well as through the increase of the outlet loss [5]. The efficiency drop for the OP380 boiler due to slagging and fouling is presented in Fig. 5 (for the period without co-firing of biomass). As you can see, after about 1000 hours of continuous operation there was a decrease in efficiency of around $0.5 \%$. 


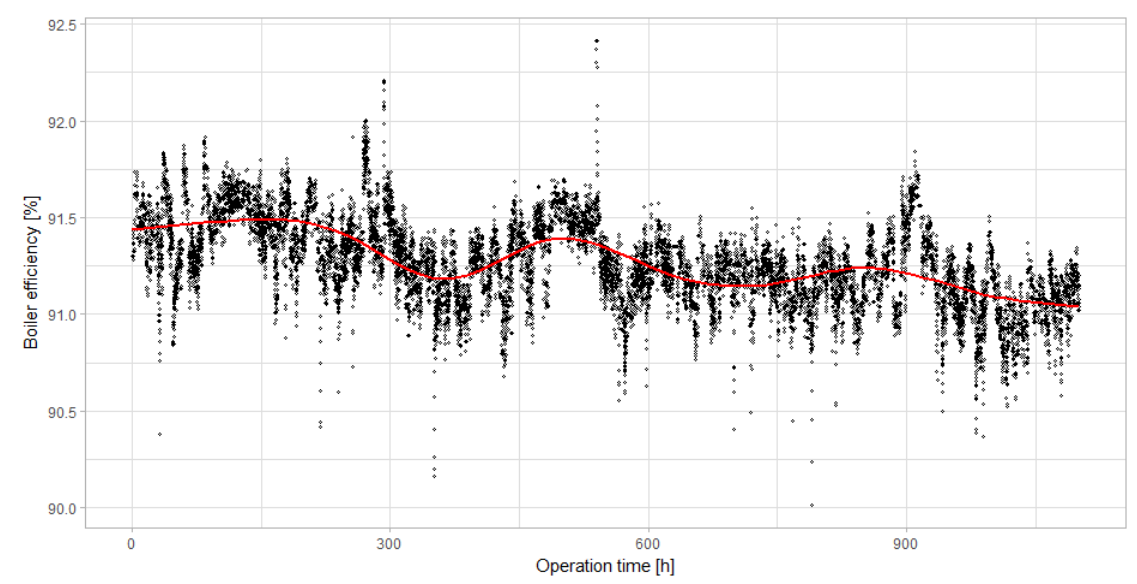

Fig. 5. Decrease in thermal efficiency of the boiler.

\section{The algorithm of soot blowers operation}

In literature, you can find positions on the methodology of calculating fouling and slagging factors. The calculations are based on the use of the heat transfer model in the boiler and the determination of the thermal power absorbed by the heating surfaces [6-8]. Taler and others [6] applied a model of heat exchange in the furnace chamber to assess the evaporator cleanliness. Pena [9] used a temporarily analysis of statistical thermal resistance between flue gases and superheated steam. The problem is also analyzed using advanced prediction models using neural networks [10] or rules of fuzzy logic [11].

This paper presents the system that continuously monitors the cleanliness degree of boiler heating surfaces for the analysis of the cleanliness factor of heating surfaces under operating conditions, which was implemented and tested on a pulverized coal-fired boiler with a maximum capacity of $380 \mathrm{t} / \mathrm{h}$. The implemented algorithm checks the qualification of individual cleaning surfaces on a regular basis, giving the production operator recommendations regarding the optimal sequence for the switching on the steam blowers. The results of the calculations are visualized on the operator's graphics, where the result of the algorithm's operation in the form of blowers configuration to be started is displayed. The system is bi-directionally communicated via the MODBUS RTU protocol with a PC calculation station, on which current calculations of individual heating surfaces are carried out based on the process data sent.

\subsection{Methodology for calculation of cleanliness factors}

The cleanliness degree of heating surface is defined as the ratio of the current thermal resistance of heat transfer between the flue gases and the heated medium to the thermal resistance corresponding to the reference clean state (Eq. 1).

$$
\xi_{i}=\frac{R_{i}}{R_{i \text { clean }}}
$$

Thermal resistance is determined based on the ebsilon-NTU method [12] (Eq. 2). The heat capacity rate is expressed by the Eq. 3 and Eq. 4, respectively on the side of the flue gas and the heating medium. 


$$
R_{i}=\frac{1}{\dot{C}_{\min _{i}} N T U_{i}}
$$

where:

NTU - dimensionless number of heat transfer units

$\dot{\mathrm{C}}_{\min }$ - the minimum value from the heat capacity rate on the flue gas side and heating medium side

$$
\begin{aligned}
& \dot{C}_{h}=\left.\dot{m}_{h} c\right|_{T_{h}^{\text {out }}} ^{T_{h}^{\text {in }}} \\
& \dot{C}_{c}=\left.\dot{m}_{c} c\right|_{T_{c}^{\text {in }}} ^{T_{c}^{\text {out }}}
\end{aligned}
$$

where:

$\dot{\mathrm{m}}_{\mathrm{h}}$ - flue gas mass flow

$\dot{\mathrm{m}}_{\mathrm{c}}-$ mass flow of the heated factor

$\mathrm{c}$ - average specific heat

index $\mathrm{h}$ - flue gas

index $\mathrm{c}$ - heated medium

The number of NTU heat transfer units is determined based on empirical correlations available in the literature [12], which are a function of the heat exchanger flow configuration (parallel, counter flow), heat transfer effectiveness and heat capacities rates.

Effectiveness is the ratio between the actual heat transfer rate and the maximum possible heat transfer rate (Eq. 5). In order to calculate effectiveness it is necessary to know the parameters both at the inlet and outlet of the heat exchanger (Fig. 6). In the case of the evaporator, after $T_{h}^{i n}$ an adiabatic combustion temperature was assumed, calculated on the basis of the energy balance taking into account the fuel and air flow rates delivered to the furnace [6]. The flue gas flow rate is determined based on the measurement of the flue gas flow in the second pass of the boiler. The live steam flow through the individual superheater stages is determined based on the mass balance using the measurement of spray water flow rate to individual stages. Enthalpy is calculated by the system on the basis of pressure and temperature measurement using thermodynamic tables. The control area and the method of determining the energy and mass balance together with the selected measuring points are presented in Fig. 7.

$$
\varepsilon_{i}=\frac{Q_{i}}{\dot{Q}_{\max i}}=\frac{\dot{m}_{i}\left(h_{c, i}^{\text {out }}-h_{c, i}^{i n}\right)}{\dot{C}_{\min _{i}}\left(T_{h, i}^{i n}-T_{c, i}^{\text {in }}\right)}
$$

The flue gas temperature is measured at the outlet from the furnace chamber using the AGAM acoustic measurement system, in the area of the RH2 superheater and in the second pass before and after the first stage of live steam, ECO water economizer and LUVO air preheaters. The unknown flue gas temperatures can be determined from the energy balance of a particular area (Eq. 6). For example, knowing the thermal power of the SH2 and the flue gas temperature at the inlet side (from the AGAM system), it is possible to calculate the temperature at the outlet, which is concurrently inlet to $\mathrm{SH} 3$ superheater. 


$$
\dot{Q}=\left.\dot{m}_{h, i} c\right|_{T_{h, i}^{\text {in }}} ^{T_{\text {in }}^{\text {out }}}\left(T_{h, i}^{\text {in }}-T_{h, i}^{\text {out }}\right)=\left.\dot{m}_{c, i} c\right|_{T_{c, i}^{\text {in }}} ^{T_{c, i}^{\text {out }}}\left(T_{c, i}^{\text {out }}-T_{c, i}^{\text {in }}\right)
$$

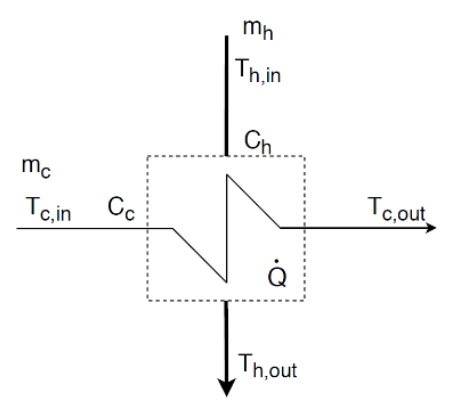

Fig. 6. The control area and the method of determining the energy balance of the heating surface.

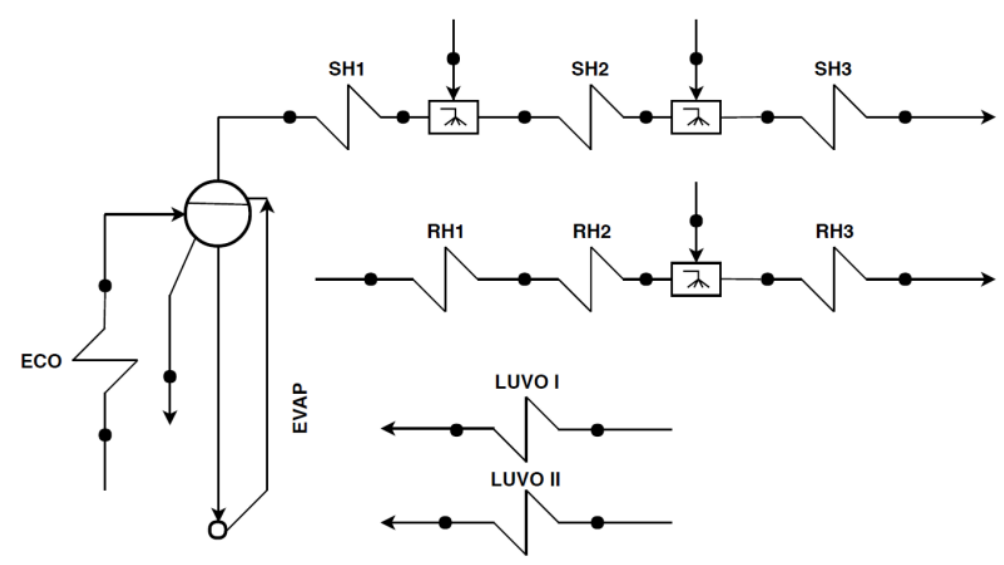

Fig. 7. The control volume for the mass and energy balance in the boiler's circuits.

The reference value of thermal resistance for the clean state can be experimentally determined during boiler operation after its thorough cleaning. Fig. 8 shows thermal resistance for the final steam superheater $\mathrm{SH} 3$ and the rotary air exchanger LUVO in the function of boiler load. Cleanliness factors are independent of boiler load changes and express the instantaneous degree of heating surface contamination with respect to the reference condition.

Fig. 9 presents the time course of the cleanliness degree of SH3 and its response to the use of a soot blower. It can be noticed a gradual increase of the coefficient and a sharp decrease due to surface cleaning. 


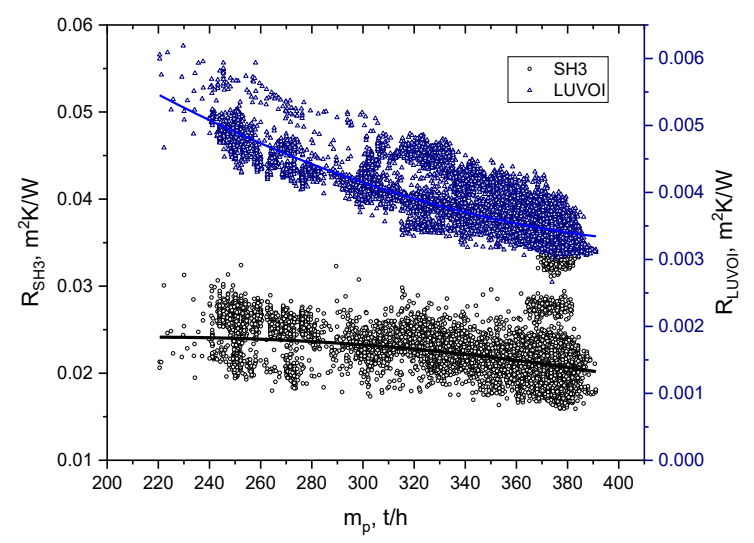

Fig. 8. SH3 and LUVO thermal resistance for the clean state.

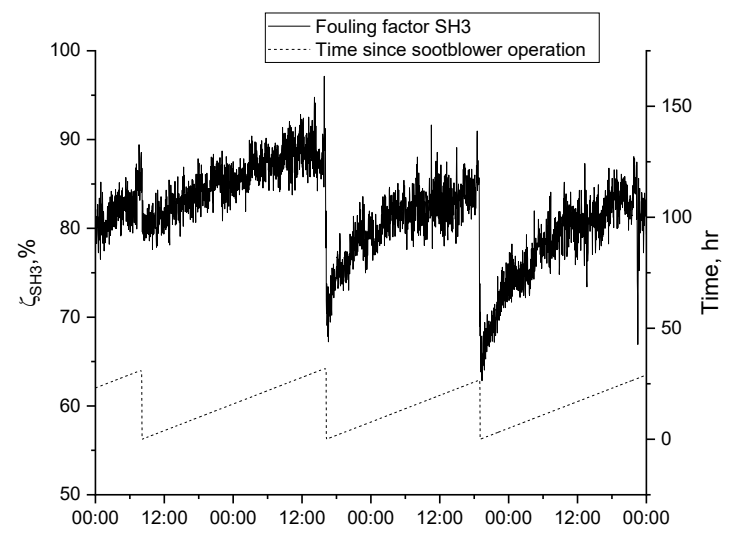

Fig. 9. The time course of the cleanliness degree of $\mathrm{SH} 3$ and its response to the use of a soot blower.

\section{Test campaign}

In order to verify methodology of calculation, the boiler operation from the clean state to the intensive fouled has been analysed. Fig. 10 shows the course of cleanliness factors for the evaporator and superheaters. In the initial phase, a decrease of the factor for SH2 is visible. This results in an increased heat transfer and consequently an increase of the spray water mass flow (Fig. 11). In the final stage one can notice the gradual increase of the RH2 and RH1 fouling factors. This corresponds to the increase flue gas negative gauge pressure before $\mathrm{SH} 1$ as well as the increase in the flue gas temperature in the RH2 region. This indicates a strong process of fouling the second boiler pass. In order to meet the reheated temperature at the outlet of the boiler, more and more fuel is supplied to the combustion chamber. In the final stage, the evaporator is also slagged. The flue gas temperature at the furnace outlet increases and the superheaters on the live steam side take up too much heat increasing the risk of exceeding the permissible tube metal temperature. The fouling of the second pass increases the flue gas velocity, which further intensifies the heat absorption by the preceding heating surfaces. 

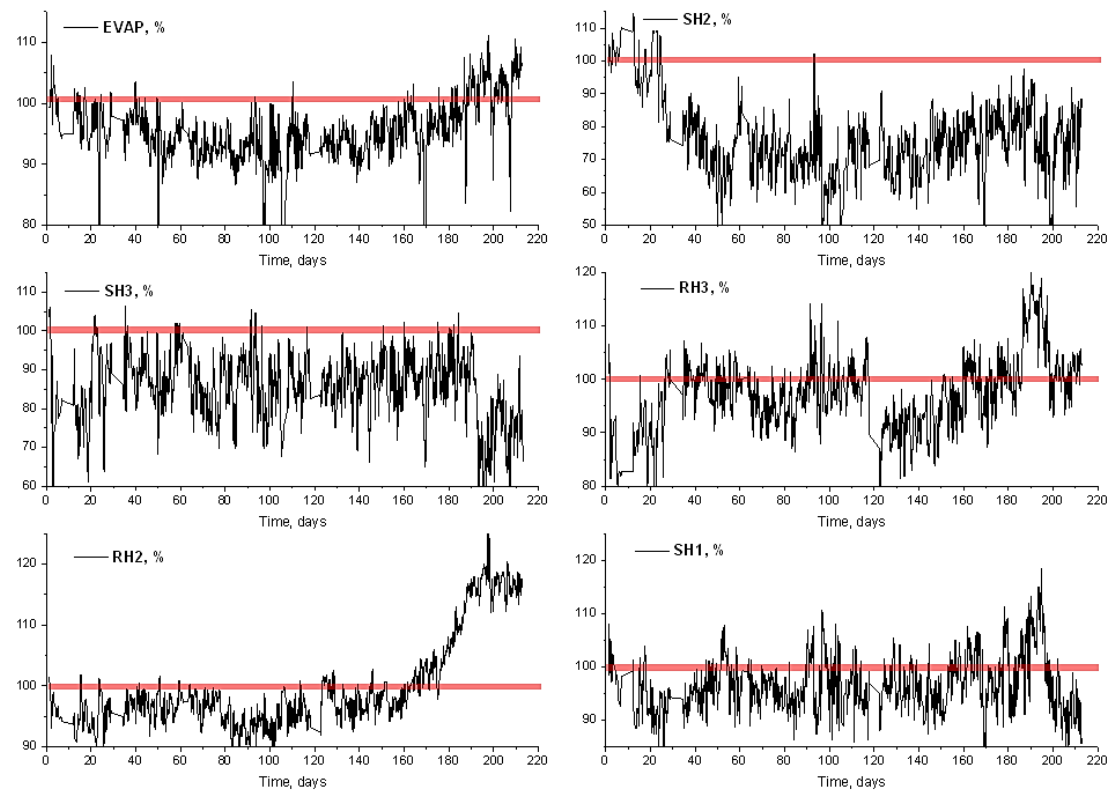

Fig. 10. The course of evaporator slagging factor, superheater and reheater fouling factors.
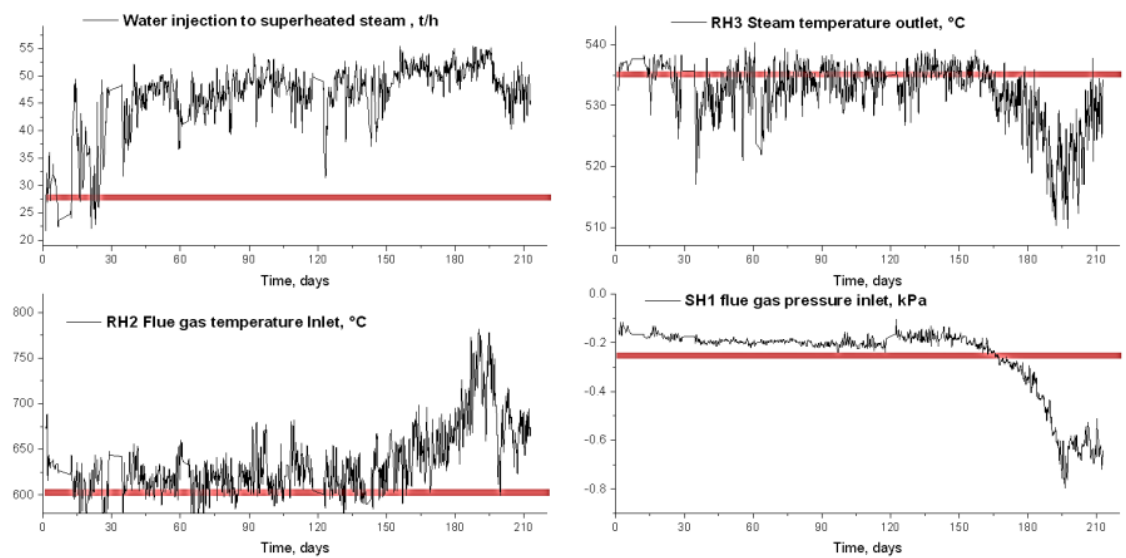

Fig. 11. The course of measured process parameters during the boiler contamination process.

\subsection{Surface cleaning according to the algorithm of soot blowers operation}

An example of boiler operation with a functioning soot blower operation control system is shown in the following figures. Fig. 12 shows the increase in the evaporator slagging factor, which is accompanied by an increase in the flue gas temperature at the outlet from the combustion chamber. Cleaning of the evaporator in accordance with the recommendation of the system leads to a reduction in the spray water mass flow rate in superheater attemperator. Fouling stage of the LUVO is presented in the Fig. 13. When soot blowers are switched on, the factor falls below the threshold value as well as air pressure drop on the surface. 


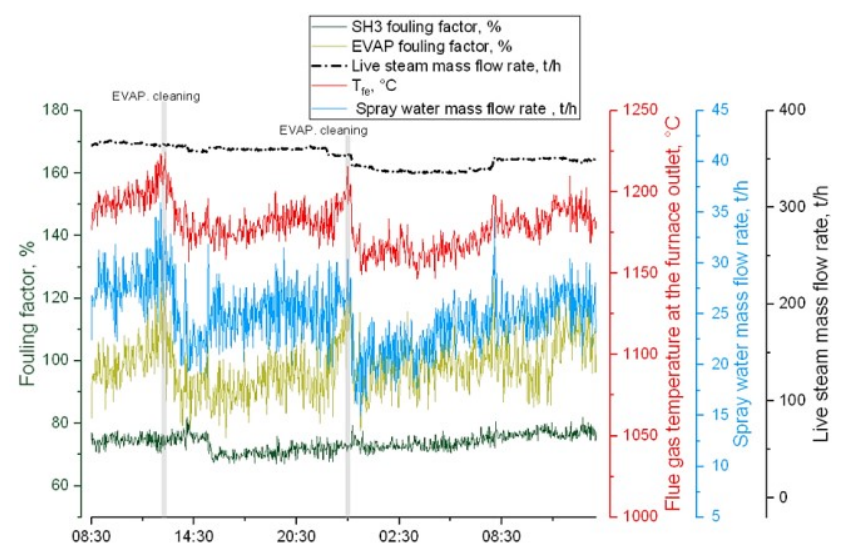

Fig. 12. The effect of cleaning the furnace chamber.

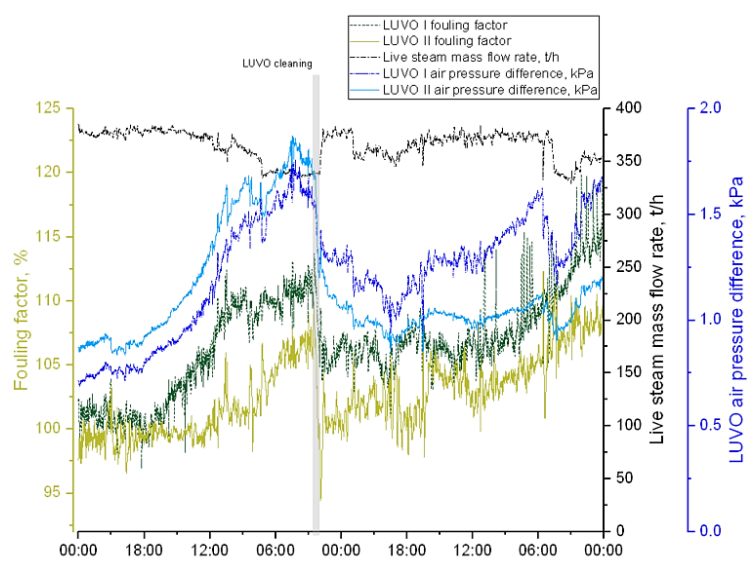

Fig. 13. The effect of cleaning the furnace chamber.

The data collected from system's operation period (approximately 5 weeks) was compared with data collected from the corresponding period without its operation. Fig. 14 shows the characteristics of the total water spray injection to the live steam and the temperature of the reheated steam at the boiler outlet, as well as an indication of the boiler load. The analysis was carried out for the same configuration of coal mills. The positive effect of the algorithm can be noticed due to reduction of water spray injection to the live steam as well as increase of reheated steam temperature, particularly in low load operation. 

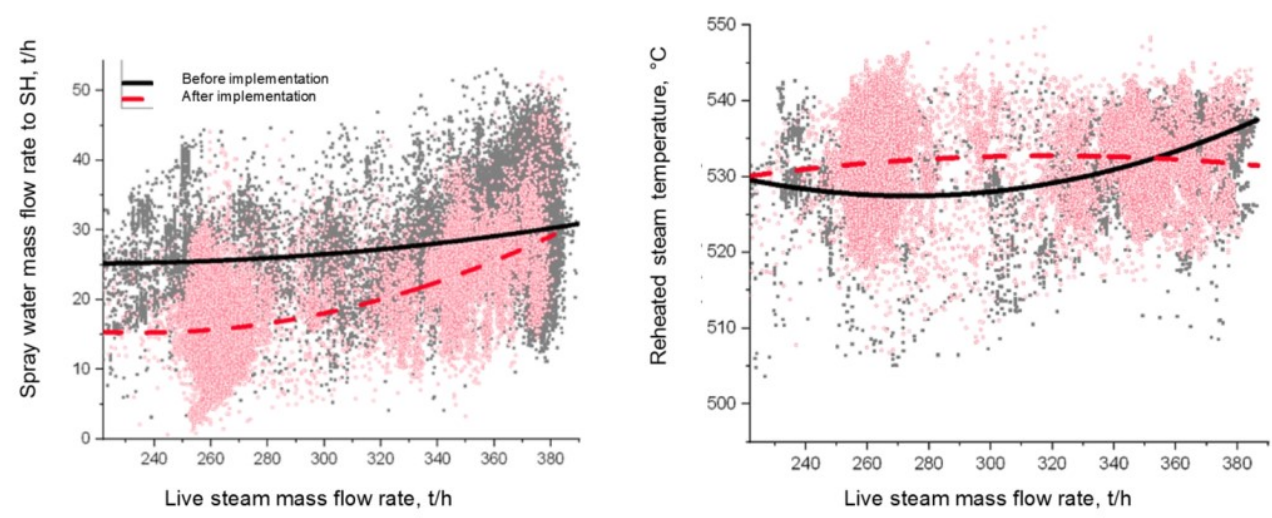

Fig. 14. Spray water mass flow rate to the superheated steam (left) and outlet reheated temperature (right) before and after implementation of the system.

\section{Summary}

The developed system for controlling the operation of soot blowers on a pulverized coal-fired boiler can be used to monitor deposit formation on all of the boiler heating surfaces in real time. Cleanliness degree calculated on the basis of the ebsilon-NTU method enable tracking of boiler fouling and slagging symptoms. The algorithm is meant to support operators in the boiler cleaning process. The goal of the system is to extend intervals between boiler cleaning which will result in the reduction of costs associated with the negative impact of boiler fouling and slagging processes. The developed tool enables an optimal boiler operation by cleaning only those surfaces that are contaminated. This allows maintaining key parameters affecting the lifetime and economy at a desirable level.

The system has been implemented in the DCS of the power unit for which it was developed. In addition, the authors have developed a dedicated system graphic that presents the current state of cleanliness of heating surfaces as well as it recommends to engage individual groups of blowers depending on the outcomes of the algorithm. After testing phase, the system is to going to be the primary tool for supervising the cleanliness of the OP380 boiler.

\section{References}

1. A. S. Benson, M. L. Jones, J. N. Harb, Ash Formation and Deposition, Fundamentals of Coal Combustion for Clean and Efficient Use, ELSEVIER, 299-373 (1993).

2. J. E. Shelby, Introduction to Glass Science and Technology, Cambridge: The Royal Society of chemistry, (1997)

3. G. Akar, S. Sen, H. Yilmaz, V. Arslan i U. Ipekoglu, Characterization of ash deposits from the boiler of Yenikoy coal-fired power plant, International Journal of Coal Geology (105), pp. 85-90, (2013)

4. M. Seggiani, Empirical correlations of the ash fusion temperatures and temperature of critical viscosity for coal and biomass ashes, Fuel (78), pp. 1121-1125, (1999)

5. G. Tsatsaronis, T. Morosuk, D. Koch, M. Sorgenfrei, Understanding the thermodynamic inefficiencies in combustion processes, Energy (62), pp. 3-11, (2013) 
6. J. Taler, M. Trojan i D. Taler, ,Monitoring of Ash Fouling and Internal Scale Deposits in Pulverized Coal Fired Boilers," Nova Science Publishers, Inc., New York, Hauppauge, USA, (2011)

7. T. Sobota, Computer monitoring and optimization of the steam boiler performance, E3S Web Conf. Volume 14, Energy and Fuels 2016, (2017)

8. P. Madejski, T. Janda, J. Taler, D. Nabagło, R. Węzik, M. Mazur, Analysis of Fouling Degree of Individual Heating Surfaces in a Pulverized Coal Fired Boiler, Journal of Energy Resources Technology, Volume 140, Issue 3, (2018)

9. B. Peña, E. Turuel, L. Diez, Towards soot-blowing optimization in superheaters, Applied Thermal Engineering, 61, pp. 737-746, (2013)

10. E. Teruel, C. Cortes, L. I. Díez i I. Arauzo, Monitoring and prediction of fouling in coalfired utility boilers using neural networks, Chemical Engineering Science 60(18), pp. 5035-5048, (2005)

11. M. Kumar, Boiler Cleanliness Factor Control Using Fuzzy Logic, International Journal for Research in Applied Science \& Engineering Technology (IJRASET), Volume 3 Issue $\mathrm{X},(2015)$

12. Y. A. Çengel, Heat transfer: a practical approach. WBC McGraw-Hill, Edition 3, (2007) 